\title{
Quantification of metal release from stainless steel electrodes during conventional and pulsed ohmic heating
}

\author{
Gianpiero Pataro ${ }^{\mathrm{a}, *}$, Giuseppe M.J. Barca ${ }^{\mathrm{b}}$, Ricardo N. Pereira ${ }^{\mathrm{c}}$, António A. Vicente ${ }^{\mathrm{c}}$, \\ José A. Teixeira ${ }^{c}$, Giovanna Ferrari ${ }^{\mathrm{a}, \mathrm{b}}$ \\ a Department of Industrial Engineering, University of Salerno, Via Giovanni Paolo II, 132-84084 Fisciano (SA), Italy \\ b ProdAl scarl, University of Salerno (Italy), Via Ponte don Melillo, 84084 Fisciano (SA), Italy \\ ' $I B B$, Institute for Biotechnology and Bioengineering, Centre for Biological Engineering, Universidade do Minho, Campus de Gualtar, 4710-057 Braga, Portugal
}

\section{A R T I C L E I N F O}

\section{Article history:}

Received 1 August 2013

Accepted 18 November 2013

Editor Proof Received Date 18 December 2013

\section{Keywords:}

Ohmic heating

Electrode corrosion

Frequency

Electric field

Electrical conductivity

$\mathrm{pH}$

Halides

\begin{abstract}
A B S T R A C T
Electrochemical reactions at the electrode-solution interface of an ohmic heater can be avoided or significantly limited by choosing appropriate processing conditions in relation to the food properties.

In the present work the effect of the electrical parameters (electric field strength and frequency of the applied current signal) and product factors (halides concentration, electrical conductivity and $\mathrm{pH}$ ) on metal release from stainless steel (type AISI 316 L) electrodes of a batch ohmic heater was investigated. In each experiment, the concentrations of the main constituents of stainless steel (iron, chromium and nickel) released in the heating medium were detected by Inductively Coupled Plasma Mass Spectrometry (ICP-MS) and Atomic Absorption Spectrophotometry (AAS).

Results showed that the rate of metal release from the electrodes to the heating medium depends on frequency and applied field strength. However, the use of ohmic heating at a higher frequency than conventional $(50 \mathrm{~Hz})$ can significantly $(p \leq 0.05)$ reduce the flux of metal ions from stainless steel electrodes. Moreover, it was also demonstrated that electrochemical phenomena occurring at the electrode-solution interface strongly depend on the composition, $\mathrm{pH}$ and electrical conductivity of the heating medium.

Industrial relevance: The magnitude of electrode material released into the heating medium during ohmic processing depends on many factors, whose effects should be known in order to define optimal treatment conditions, electrode material and food properties able to avoid or minimize the undesired phenomenon of contamination of the food product, electrode-fouling and electrode corrosion. This paper contributes to clarifying the effects of electric field strength applied as well as electrical conductivity, $\mathrm{pH}$, and presence of halides in the heating medium on electrode corrosion or release of electrode materials during high frequency (25 $\mathrm{kHz}$, bipolar square wave) pulsed power $\mathrm{OH}$ in comparison with conventional ( $50 \mathrm{~Hz}$ sine wave) $\mathrm{OH}$. Interestingly, the use of sufficiently large frequencies may avoid or reduce the extent of electrochemical reactions at the electrode interface, minimizing corrosion and leakage of metals to the heating medium, even when electrode material of low cost and electrochemically active like stainless steel is used.
\end{abstract}

(C) 2013 Elsevier Ltd. All rights reserved

\section{Introduction}

Ohmic heating $(\mathrm{OH})$, a well-known electroheating technique, has been extensively studied in the past two decades and today commercial scale equipments are operated for thermal processing of a broad range of viscous, liquid and multiphase food products (Pereira \& Vicente, 2010). In respect to this, several research works were already developed in order to contribute to the validation of ohmic heating technology for use in several food industrial applications including the stabilization of baby foods (Icier \& Ilicali, 2005), pasteurization of orange juice (Leizerson \& Shimoni, 2005) and milk (Pereira, Martins, \& Vicente, 2008), as well as aseptic processing of particulate products, such as

\footnotetext{
* Corresponding author. Tel.: + 39 089969439; fax: + 39089964168. E-mail address: gpataro@unisa.it (G. Pataro).
}

broccoli in cheese sauce, shrimp gumbo, strawberries in glaze, chicken, stews, or pasta in tomato based sauce, cauliflower in sauce, apricots in syrup (Eliot-Godrereaux, Zuberb, \& Goullieux, 2001; Pataro, Donsì, \& Ferrari, 2011; Yang et al., 1997; Zoltai \& Swearingen, 1996).

In spite of such achievements, a deeper understanding of all undesirable electrochemical reactions which occur at the electrode-liquid food interface as a result of the passage of an electric current (usually alternating) through the ohmic heater, is still a matter of concern. In fact, from an electrochemical point of view, an ohmic heater which consists of two metal electrodes placed in direct contact with an electrolytic solution and electrically connected to a power generator, acts as an electrochemical cell (Amatore, Berthou, \& Hebert, 1998; Tzedakis, Basseguy, \& Comtat, 1999). The current flowing in the metal electrodes consists of free electrons while, in the liquid food solution, which is an electrolyte, the current is carried by ions rather than by free electrons (Roodenburg, 
Morren, Berg, \& de Haan, 2005a). At each electrode-solution interface, in order to maintain the condition of electroneutrality, an ionic double layer, which consists of charged particles and/or of oriented dipoles, is developed even if no external voltage is applied to the electrodes. This layer, which behaves as an electrical capacitor, is often called double layer capacitor. When a potential difference is applied across the electrodes, a process of electric charging of the double layer takes place (Bockris, Reddy, \& Gamboa-Aldeco, 2002; Gileadi, 1993a). During the charging process of the double layer capacitors, as long as the potential drop within them remains smaller than any threshold potential above which Faradaic reactions occur at the electrode interface, the current flow would be purely capacitive, avoiding oxidative and reductive reactions at the electrode-solution interfaces. Once the potential drop across the double layer overcomes the threshold voltage, in order to preserve the charge conservation principle, electrochemical reactions will occur: oxidation reaction (i.e. loss of electrons) will take place at the electrode surface which behaves as anode and reduction reaction (i.e. gain of electrons) at the electrode surface which behaves as cathode (Morren, Roodenburg, \& de Haan, 2003). Under alternating current conditions, cathode and anode interchange occurs according to the frequency. Therefore, the electrochemical reactions of oxidation and reduction occur alternatively at the same electrode site. These reactions, which typically occur in ohmic heaters powered at low frequency (50-60 Hz), are undesirable and must be minimized since they may lead to undesired electrolysis of the heating medium, degradation of nutrients, electrode-fouling as well as electrode material migration into the heating medium (electrode corrosion) which could shorten the electrode life time and contaminate foods (Assiry, Sastry, \& Samaranayake, 2006; Ayadi, Leuliet, Chopard, Berthou, \& Lebouche, 2004; Jun, Sastry, \& Samaranayake, 2007; Samaranayake \& Sastry, 2005; Stancl \& Zitny, 2010).

In spite of this, an extremely limited number of data are available on electrochemical reactions occurring under $\mathrm{OH}$ conditions. It has been found that the extent of these electrochemical reactions may be limited by either using high-capacitance electrode material (Amatore et al., 1998; Samaranayake \& Sastry, 2005), or by using an increased frequency above $50 \mathrm{~Hz}$ (Amatore et al., 1998). In both cases the objective is to avoid full charging of the double layer capacitors before the electric field polarity of the applied voltage is reversed. However, although a high double layer capacitance of the electrode material can limit electrochemical processes, the type and extent of electrochemical reactions are also determined by the chemical nature of the electrode surface (Samaranayake \& Sastry, 2005). As a result, it appears that the inert electrochemical behavior of platinized-titanium electrodes could be the best choice for $\mathrm{OH}$ of food products with low frequency $(50 \mathrm{~Hz})$ alternating currents, over low cost and commonly used stainless steel electrodes.

On the other hand, the positive effect of higher frequency could allow avoiding or reducing the extent of electrochemical reactions, regardless the electrode material and environmental conditions. However, although it has been known for a long time (Amatore et al., 1998), only more recently, given the developments in power technology, the beneficial effect of high frequency has been studied in detail by Samaranayake, Sastry, and Zhang (2005) and Jun et al. (2007). These authors demonstrated that the use of pulsed ohmic heating at frequencies of 4 and $10 \mathrm{kHz}$, namely the use of bipolar square pulses at high frequency with a given duty cycle derived from an IGBT switching device, is capable of significantly reducing the electrochemical reactions of stainless steel, titanium, and platinized-titanium electrodes, compared with conventional $60 \mathrm{~Hz}$ ohmic heating.

Besides the above factors, it should be taken into account that also factors linked to the food products such as composition (halides concentration), $\mathrm{pH}$ and electrical conductivity $(\sigma)$ may significantly affect the extent of electrochemical reactions. However, to our knowledge, only one paper deals with the effect of $\mathrm{pH}$ on electrochemical reactions during ohmic heating (Samaranayake \& Sastry, 2005), while studies on the effect of $\sigma$ of the heating media and halide concentration have yet to be published.

The objective of this work was to study the effect of high frequency (25 kHz, bipolar square wave) pulsed power $\mathrm{OH}$ on metal release from stainless steel (type AISI 316 L) electrodes of a batch ohmic heater in comparison with conventional $50 \mathrm{~Hz}$ (sine wave) $\mathrm{OH}$. In this frame, the effects of electric field strength and of product characteristics such as chloride concentration, electrical conductivity, and $\mathrm{pH}$ were also investigated.

\section{Materials and methods}

\subsection{Experimental setup}

Experiments were carried out using two similar laboratory scale batch unstirred ohmic heaters connected, respectively, to two different power generators: a high frequency ( $25 \mathrm{kHz}$, bipolar square wave) pulsed power generator and a conventional low frequency $(50 \mathrm{~Hz}$, sine wave) generator. Fig. 1 shows a generalized simplified scheme of the two ohmic heating systems.

The high frequency ohmic system consisted of a static ohmic heater made of an open cylindrical polycarbonate tube $(3 \mathrm{~cm}$ in diameter, $5 \mathrm{~cm}$ in length) limited by two disk-shaped stainless steel (type AISI $316 \mathrm{~L}$ ) electrodes isolated at each edge with Teflon pressure caps. The electrodes were connected to a $15 \mathrm{~kW}$ power supply unit (model GR1520, Micropi Elettronica, Saviano, Italy) able to provide electric current in the form of bipolar square waves at $25 \mathrm{kHz}$ with adjustable amplitude (from 0 to $1500 \mathrm{~V}$ ) and duty cycle and limited only by maximum current value of $20 \mathrm{~A}$. For the experiments of this study a duty cycle of $100 \%$ was used in order to obtain heating of the treatment media in a reasonable time regardless of the medium conductivity and applied voltage.

The low frequency ohmic heating system consisted of an ohmic heater made of an open cylindrical Pyrex glass tube $(30 \mathrm{~cm}$ total length and $2.3 \mathrm{~cm}$ inner diameter) closed at the ends with two disk-shaped stainless steel (type AISI 316 L) electrodes isolated with Teflon pressure caps. For the experiments of this study, the electrodes were placed at a distance of $5 \mathrm{~cm}$ and connected to an alternating current source (ChuanHsin, Taiwan), able to provide up to a maximum a.c. voltage of 220 Vrms at $50 \mathrm{~Hz}$.

In both ohmic systems, a data-logger was employed to record continuously and simultaneously voltage across and current through the samples as measured by special voltage and current transducers, as well as product temperature measured by a T-type Teflon coated thermocouple (1 $\mathrm{mm}$ in diameter) placed at the geometrical center of the ohmic heater.

\subsection{Heating media}

Two different buffer solutions (Trizma- $\mathrm{HCl}$ and Mcllvaine) were used as heating mediums. Trizma- $\mathrm{HCl}$ buffer solutions $(0.05 \mathrm{~mol} / \mathrm{L})$ were prepared by dissolving $7.02 \mathrm{~g}$ of Trizma hydrochloride $\left[\mathrm{NH}_{2} \mathrm{C}\left(\mathrm{CH}_{2} \mathrm{OH}\right)_{3} \cdot \mathrm{HCl}\right]$ (Sigma-Aldrich, Italy), and $0.67 \mathrm{~g}$ of Trizma base $\left[\mathrm{NH}_{2} \mathrm{C}\left(\mathrm{CH}_{2} \mathrm{OH}\right)_{3}\right]$ (Sigma-Aldrich, Italy) in distilled water up to a final volume of $1 \mathrm{~L}$. The $\mathrm{pH}$ of the solution was 7 . The initial electrical conductivity was adjusted to the final values of 1,3 , and $5 \mathrm{mS} / \mathrm{cm}$ at $25{ }^{\circ} \mathrm{C}$ by adding distilled water, at which correspond chloride concentrations of, respectively, $0.0103,0.0321$ and $0.0627 \mathrm{~mol} / \mathrm{L}$ (Table 1). Citrate-phosphate buffer solutions (Mcllvaine) were prepared by mixing a solution $(0.1 \mathrm{~mol} / \mathrm{L})$ of citric acid monohydrate with a solution $(0.2 \mathrm{~mol} / \mathrm{L})$ of disodium hydrogenphosphate. The acid to salt ratio was set in order to obtain buffer solutions with two different $\mathrm{pH}$ values ( 3.5 and 7). The initial electrical conductivity of the solution was adjusted to the final values of 1,3 , and $5 \mathrm{mS} / \mathrm{cm}$ at $25^{\circ} \mathrm{C}$ by adding distilled water. Based on its formulation, the concentration of halides was assumed to be zero independently of the electrical conductivity (Table 1). 


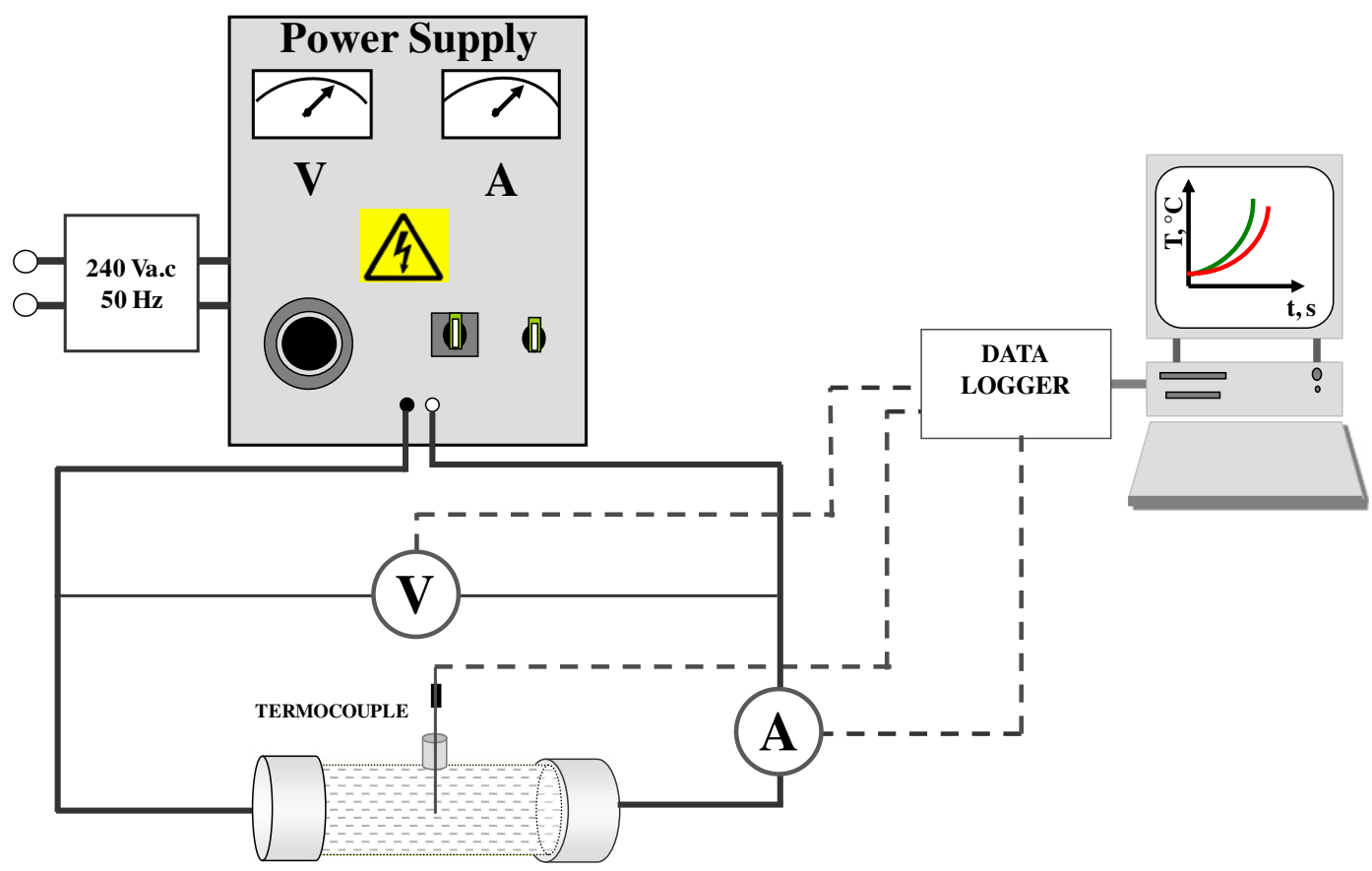

OHMIC HEATER

Fig. 1. Schematic diagram of the experimental setup.

\subsection{Experimental procedure}

For each experimental run heating medium volumes of $21 \mathrm{~mL}$ and $28 \mathrm{~mL}$ were loaded in the ohmic heater connected to the low and high frequency $\mathrm{OH}$ system, respectively. The power supply was subsequently turned on and the sample was heated from an initial temperature $\left(T_{i}\right)$ of $25{ }^{\circ} \mathrm{C}$ up to a final temperature $\left(T_{f}\right)$ of about $90{ }^{\circ} \mathrm{C}$ by applying a constant voltage of 100 and $200 \mathrm{~V}$. At the end of the heating phase, the power supply was turned off and the product was rapidly removed from the ohmic heater, collected into plastic test tubes and analyzed to evaluate the concentration of metal ions in the solution. For each set of experiments, a corresponding volume of the respective unheated medium was taken and analyzed as blank.

Between two consecutive experimental runs, a sufficient amount of distilled water was used in order to cool down the ohmic heater as well as to thoroughly rinse the system. To ensure the homogeneity of the samples of each set of experiments the solutions were prepared all in one time. In addition, separate couples of electrodes were used for experiments carried out with Trizma- $\mathrm{HCl}$ and McIlvaine buffer solutions, respectively, in the case of the high frequency experiments. For low frequency experiments separate couples of electrodes were used for each experimental run.

Table 1

Experimental variables and processing conditions.

\begin{tabular}{lll}
\hline \multirow{2}{*}{ Experimental variables } & \multicolumn{2}{l}{ Processing conditions } \\
\cline { 2 - 3 } & Mcllvaine & Trizma-HCl \\
\hline$\sigma(\mathrm{mS} / \mathrm{cm})$ & $1-3-5$ & $1-3-5$ \\
$E(\mathrm{~V} / \mathrm{cm})$ & $20-40$ & $20-40$ \\
Frequency $(\mathrm{Hz})$ & $50-25,000$ & $50-25,000$ \\
$\mathrm{pH}$ & $3.5-7.0$ & 7.0 \\
Chloride concentration $^{\mathrm{a}}(\mathrm{mol} / \mathrm{L})$ & 0.0 & $0.0103-0.0321-0.0627$ \\
\hline
\end{tabular}

${ }^{a}$ Chloride concentration corresponding to the electrical conductivity values.

\subsection{Effect of electrical parameters and medium composition}

$\mathrm{OH}$ experiments were carried to study the effect of electric field strength and frequency of the current signal on metal release from electrodes into two heating media (Trizma- $\mathrm{HCl}$ and Mcllvaine buffer) with a different composition (halides concentration) but with the same $\mathrm{pH}$ (7) and electrical conductivity $\left(3 \mathrm{mS} / \mathrm{cm}\right.$ at $\left.25{ }^{\circ} \mathrm{C}\right)$. Two different electric field strength values were applied, 20 and $40 \mathrm{~V} / \mathrm{cm}$, by imposing two different constant voltages of, respectively, 100 and $200 \mathrm{~V}$ at both $50 \mathrm{~Hz}$ and $25 \mathrm{kHz}$ (Table 1).

\subsection{Effect of chemical-physical properties of the heating medium}

Two sets of experiments were carried out to obtain insight on the effects of $\sigma$ and $\mathrm{pH}$ of the heating medium on metal release during ohmic heating. In the first set, Trizma- $\mathrm{HCl}$ and Mcllvaine buffer solutions $(\mathrm{pH}=7)$ of three different electrical conductivities $(\sigma=1,3$, and $5 \mathrm{mS} / \mathrm{cm}$ at $25{ }^{\circ} \mathrm{C}$ ) were ohmically heated by applying a constant voltage of $200 \mathrm{~V}$ at both $50 \mathrm{~Hz}$ and $25 \mathrm{kHz}$. In the second set of experiments, McIlvaine buffer solutions $(\sigma=3 \mathrm{mS} / \mathrm{cm})$ of different $\mathrm{pH}$ values (3.5 and 7) were ohmically heated by applying a constant voltage of $200 \mathrm{~V}$ at both $50 \mathrm{~Hz}$ and $25 \mathrm{kHz}$ (Table 1).

\subsection{Quantification of metals}

Total metal ion concentrations of $\mathrm{Fe}, \mathrm{Cr}$, and $\mathrm{Ni}$ released from stainless steel electrodes into ohmically heated buffer solutions were measured using an Atomic Absorption Spectrophotometry (AAS) (Varian Spectra AA-400, Mulgrave, Victoria, Australia), for samples treated at $50 \mathrm{~Hz}$, and an Inductively Coupled Plasma Mass Spectrometry (ICP-MS) (7500c ICP-MS, Agilent Technologies, USA), for samples treated at $25 \mathrm{kHz}$. Preliminary experiments (data not shown) revealed that, although the different accuracy of the two methods, within the range of metal ions concentrations detected in the ohmically heated sample using the current signal at $50 \mathrm{~Hz}$, the two methods have shown comparable results. 
In the beginning of each session, both AAS and ICP-MS were calibrated with certified standards and the best calibration curves were chosen. In addition, for the quantitative analyses by ICP-MS, before each measurement, about 6 drops of concentrated nitric acid $(65 \% \mathrm{w} / \mathrm{v})$ (Sigma-Aldrich) were added to the collected heated and unheated samples in order to stabilize samples. After calibration, the concentration (in $\mathrm{mg} / \mathrm{L}$ ) of the metallic species of interest dissolved in heated and unheated samples were measured immediately after each set of experiments in the same measurement session of either AAS or ICPMS, in order to avoid any changes of conditions of the calibration curves. The limits of detection (LOD) for iron, chromium, and nickel are, respectively, of $0.06,0.06$, and $0.1 \mathrm{mg} / \mathrm{L}$, for the used AAS and 2.29, 5.41, and $3.46 \mu \mathrm{g} / \mathrm{L}$ for the used ICP-MS.

For all the measurements carried out with both AAS and ICP-MS techniques, the actual concentration of metal $\left(C_{m i}\right.$, in $\left.\mathrm{mg} / \mathrm{L}\right)$ released from the electrodes into the solution during $\mathrm{OH}$ was evaluated as the difference between the concentrations measured in heated and unheated samples. However, the amount of metal released depends upon heating time, which changes with both $\sigma$ of the heating medium and the applied voltage, as well as with the electrode area in contact with the solution which, in turn, affects the amount of current passing through the ohmic heater. Therefore, for the purpose of comparison, the actual amount of metal released during $\mathrm{OH}$ was normalized on the basis of both heating time $\left(t_{h}\right.$, in $\left.\mathrm{s}\right)$ and effective electrode area $\left(A\right.$, in $\left.\mathrm{mm}^{2}\right)$ and results were represented, for each metallic element of interest, in terms of corrosion rate by the average flux of metal ions $N_{m i}$ (in $\mathrm{mg} \mathrm{mm}^{-2} \mathrm{~s}^{-1}$ ) (Eq. (1)):

$N_{m i}=\frac{C_{m i} \cdot v_{O H}}{(2 \cdot A) \cdot t_{h}}$

where $v_{O H}$ is the volume of the ohmically treated sample and the factor 2 was used to take into account that under alternating/bipolar current conditions, the electrochemical reactions of oxidation responsible for metal release occur alternatively at both the electrodes according to the frequency. The value of $N_{m i}$ was normalized with treatment time and electrode area once these values were not being kept constant between experiments (electrode area changed between high and low frequency experiments and treatment time changed for different values of voltage and conductivity).

\subsection{Statistical analyses}

In each processing condition and for both buffer solutions, the experiments were carried out in triplicate and each collected sample was analyzed in duplicate. The mean values and standard deviations of the experimental data were calculated.

Differences among corrosion rates of individual metal ions obtained for different electric field strengths, operating frequencies, electrical conductivities, $\mathrm{pH}$ and chloride concentrations were analyzed by oneway ANOVA in order to determine whether different values of these operating parameters led to a significant difference in the release of metals. When significant differences were detected, the Tukey test was performed to determine which particular means were significantly different $(p \leq 0.05)$. Statistical Analyses were carried out using the toolbox Daniel's XL 6.21.

\section{Results and discussion}

\subsection{Effect of electric field and treatment frequency}

Tables 2 and 3 show the average flux of metal ions of the main elements of stainless steel electrodes $(\mathrm{Fe}, \mathrm{Cr}, \mathrm{Ni})$ in both Trizma- $\mathrm{HCl}$ and Mcllvaine buffer solutions ( $\mathrm{pH}=7, \sigma=3 \mathrm{mS} / \mathrm{cm}$ ) as a function of the field strength applied and at different frequencies of the current signal. Results show that, regardless of the heating medium, the flux
Table 2

Flux of Fe, $\mathrm{Cr}$, and Ni in Trizma-HCl buffer solution ( $\mathrm{pH}=7, \sigma=3 \mathrm{mS} / \mathrm{cm})$ as a function of the electric field strength applied and frequency $(f) . T_{i}=25{ }^{\circ} \mathrm{C} ; T_{f}=90{ }^{\circ} \mathrm{C}$.

\begin{tabular}{lrrlll}
\hline \multirow{2}{*}{$\begin{array}{l}\text { Metallic } \\
\text { element }\end{array}$} & Corrosion rate $\cdot 10^{7}\left(\mathrm{mg} / \mathrm{mm}^{2} / \mathrm{s}\right)^{*}$ & & \\
\cline { 2 - 3 } \cline { 5 - 6 } & $f=50 \mathrm{~Hz}$ & & $f=25 \mathrm{kHz}$ & \\
\cline { 2 - 3 } \cline { 5 - 6 } & $E=20 \mathrm{~V} / \mathrm{cm}$ & $E=40 \mathrm{~V} / \mathrm{cm}$ & & $E=20 \mathrm{~V} / \mathrm{cm}$ & $E=40 \mathrm{~V} / \mathrm{cm}$ \\
\hline $\mathrm{Fe}$ & $10.818^{\mathrm{a}, \mathrm{A}}(1.640)$ & $67.064^{\mathrm{b}, \mathrm{A}}(2.032)$ & & $0.067^{\mathrm{a}, \mathrm{B}}(0.002)$ & $0.433^{\mathrm{b}, \mathrm{B}}(0.031)$ \\
$\mathrm{Cr}$ & $0.510^{\mathrm{a}}(0.243)$ & $2.158^{\mathrm{b}}(0.097)$ & $<$ LOD & $<$ LOD \\
$\mathrm{Ni}$ & $1.564^{\mathrm{a}}(1.113)$ & $8.348^{\mathrm{b}}(1.542)$ & $<$ LOD & $<$ LOD \\
\hline
\end{tabular}

$\overline{\mathrm{a}-\mathrm{b}}$ Means with different superscript lowercase letters for each frequency value and metallic element are significantly different $(p \leq 0.05)$.

${ }^{\mathrm{A}-\mathrm{B}}$ Means with different superscript uppercase letters for each metallic element and field strength and different frequencies are significantly different $(p \leq 0.05)$.

LOD means Limit of Detection.

* Numbers in parentheses indicate standard deviations of mean $(n=6)$ corrosion rate.

of metal ions is related to the composition of the stainless steel electrodes and depends on the frequency and the applied field strength. In particular, for each heating medium and frequency investigated, the flux of metal ions significantly ( $p \leq 0.05$ ) increases with field strength and, hence, the voltage applied increases. These results agree with the fact that the rate of charge transfer through the electrode-solution interface is strongly related to the applied potential (Stancl \& Zitny, 2010). Moreover, for each heating medium and field strength applied, the flux of metal ions significantly ( $p \leq 0.05$ ) decreases when the frequency of the current signal increases. In particular, the comparison between the results of Tables 2 and 3 for the same heating medium, clearly shows that the flux of metal ions in the ohmic heater powered by the high frequency $(25 \mathrm{kHz})$ pulsed power generator is about two orders of magnitude smaller than that measured in the ohmic heater connected with the conventional low frequency ( $50 \mathrm{~Hz}$, sine wave) generator. These results can be explained bearing in mind that under alternating current, when the polarity of the potential is reversed, the electrodesolution interface behaves like a capacitor which charges and discharges according to the frequency (Amatore et al., 1998). Thus, the use of low frequency current signal may determine the full charging of the electrodes double layer up to exceeding the threshold value corresponding to the onset of electrode reactions. This will cause electrode corrosion and an increased metal release into the solution and, hence, food contamination (Amatore et al., 1998). On the other hand, the use of higher frequency may avoid the full charging of the two double layers maintaining the potential drop across them at low values. As a result, the large current flow required for fast heating of food product can be provided without electrolysis of the solution and electrode corrosion (Amatore et al., 1998).

For product safety, the type and amount of electrode material released in $\mathrm{OH}$ processed food must be within health safety regulations before introducing it as processed food to the market. We compared the actual metal concentrations detected after each $\mathrm{OH}$ treatment with the maximum allowable values of iron $(200 \mu \mathrm{g} / \mathrm{L})$, chromium $(50 \mu \mathrm{g} / \mathrm{L})$, and

Table 3

Flux of $\mathrm{Fe}, \mathrm{Cr}$, and $\mathrm{Ni}$ in Mclvaine buffer solution $(\mathrm{pH}=7, \sigma=3 \mathrm{mS} / \mathrm{cm})$ as a function of the electric field strength applied and frequency $(f) . T_{i}=25{ }^{\circ} \mathrm{C} ; T_{f}=90^{\circ} \mathrm{C}$.

\begin{tabular}{llrlll}
\hline \multirow{2}{*}{$\begin{array}{l}\text { Metallic } \\
\text { element }\end{array}$} & \multicolumn{2}{l}{ Corrosion rate $\cdot 10^{7}\left(\mathrm{mg} / \mathrm{mm}^{2} / \mathrm{s}\right)^{*}$} & & \\
\cline { 2 - 3 } & $f=50 \mathrm{~Hz}$ & & & $f=25 \mathrm{kHz}$ & \\
\cline { 2 - 3 } \cline { 5 - 6 } & $E=20 \mathrm{~V} / \mathrm{cm}$ & $E=40 \mathrm{~V} / \mathrm{cm}$ & & $E=20 \mathrm{~V} / \mathrm{cm}$ & $E=40 \mathrm{~V} / \mathrm{cm}$ \\
\hline $\mathrm{Fe}$ & $1.713^{\mathrm{a}, \mathrm{A}}(0.370)$ & $6.387^{\mathrm{b}, \mathrm{A}}(0.980)$ & & $0.039^{\mathrm{a}, \mathrm{B}}(0.009)$ & $0.125^{\mathrm{b}, \mathrm{B}}(0.021)$ \\
$\mathrm{Cr}$ & $0.253^{\mathrm{a}}(0.0650)$ & $1.342^{\mathrm{b}}(0.163)$ & $<$ LOD & $<$ LOD \\
$\mathrm{Ni}$ & $0.160^{\mathrm{a}}(0.043)$ & $1.167^{\mathrm{b}}(0.212)$ & $<$ LOD & $<$ LOD \\
\hline
\end{tabular}

${ }^{\mathrm{a}-\mathrm{b}}$ Means with different superscript lowercase letters for each frequency value and metallic element are significantly different $(p \leq 0.05)$.

${ }^{A-B}$ Means with different superscript uppercase letters for each metallic element and field strength and different frequencies are significantly different $(p \leq 0.05)$.

LOD means Limit of Detection.

* Numbers in parentheses indicate standard deviations of mean $(n=6)$ corrosion rate. 
Table 4

Flux of Fe, $\mathrm{Cr}$, and $\mathrm{Ni}$ in Trizma-HCl buffer solution $(\mathrm{pH}=7)$ as a function of the electrical conductivity and frequency $(f) . E=40 \mathrm{~V} / \mathrm{cm} ; T_{i}=25{ }^{\circ} \mathrm{C} ; T_{f}=90{ }^{\circ} \mathrm{C}$.

\begin{tabular}{|c|c|c|c|c|c|c|}
\hline \multirow[t]{3}{*}{ Metallic element } & \multicolumn{6}{|c|}{ Corrosion rate $\cdot 10^{7}\left(\mathrm{mg} / \mathrm{mm}^{2} / \mathrm{s}\right)^{*}$} \\
\hline & \multicolumn{3}{|l|}{$f=50 \mathrm{~Hz}$} & \multicolumn{3}{|l|}{$f=25 \mathrm{kHz}$} \\
\hline & $\sigma=1 \mathrm{mS} / \mathrm{cm}$ & $\sigma=3 \mathrm{mS} / \mathrm{cm}$ & $\sigma=5 \mathrm{mS} / \mathrm{cm}$ & $\sigma=1 \mathrm{mS} / \mathrm{cm}$ & $\sigma=3 \mathrm{mS} / \mathrm{cm}$ & $\sigma=5 \mathrm{mS} / \mathrm{cm}$ \\
\hline $\mathrm{Fe}$ & $4.275^{\mathrm{a}, \mathrm{A}}(0.910)$ & $67.064^{\mathrm{b}, \mathrm{A}}(2.032)$ & $91.780^{\mathrm{c}, \mathrm{A}}(5.110)$ & $0.024^{\mathrm{a}, \mathrm{B}}(0.009)$ & $0.433^{\mathrm{b}, \mathrm{B}}(0.031)$ & $\begin{array}{l}0.495^{\mathrm{c}, \mathrm{B}} \\
(0.023)\end{array}$ \\
\hline $\mathrm{Cr}$ & $0.147^{\mathrm{a}}(0.092)$ & $2.158^{\mathrm{b}}(0.097)$ & $2.281^{\mathrm{b}}(1.030)$ & $<\mathrm{LOD}$ & $<\mathrm{LOD}$ & $<\mathrm{LOD}$ \\
\hline $\mathrm{Ni}$ & $0.689^{a}(0.182)$ & $8.348^{\mathrm{b}}(1.542)$ & $10.334^{\mathrm{b}}(1.670)$ & $<\mathrm{LOD}$ & $<$ LOD & $<\mathrm{LOD}$ \\
\hline
\end{tabular}

$\overline{a-b-c}$ Means with different superscript lowercase letters for each frequency value and metallic element are significantly different ( $p \leq 0.05$ ).

${ }^{\mathrm{A}-\mathrm{B}}$ Means with different superscript uppercase letters for each metallic element and $\sigma$ values and different frequencies are significantly different ( $p \leq 0.05$ ).

LOD means Limit of Detection.

$*$ Numbers in parentheses indicate standard deviations of mean $(n=6)$ corrosion rate.

nickel $(20 \mu \mathrm{g} / \mathrm{L})$ mentioned in the European legislation for drinking water (Directive No 98/83/EG), which is the only one which mentions all the metallic elements examined in this work. It is worth noting that, regardless of the heating medium, while the concentration of metallic elements dissolved in the solution heated with higher frequency $\mathrm{OH}$ generator were largely within the legislation limits, those detected with conventional low frequency $\mathrm{OH}$ were found to be well above the legal limits.

\subsection{Effect of composition, $\sigma$, and $\mathrm{pH}$ of the heating medium}

The composition as well as chemical-physical properties of the heating medium can significantly affect the type and the extent of the electrochemical reactions that occur at the electrode-solution interface (Pataro, Donsì, \& Ferrari, 2012; Samaranayake \& Sastry, 2005).

Results displayed in Tables 2 and 3 allow comparing the flux of metal ions in two different buffer solutions with similar $\sigma$ and $\mathrm{pH}$ values after $\mathrm{OH}$ under the same processing conditions. It can be seen that, for each field strength applied, the flux of metal ions from the electrodes into the Trizma-HCl buffer is about one order of magnitude greater than the one measured into the Mcllvaine buffer solution after conventional low frequency $\mathrm{OH}$, and less than one order of magnitude at higher frequency. In addition, for the Mcllvaine buffer and at the highest frequency the concentrations of chromium and nickel were found to be below the correspondent LOD values. This difference can be likely attributed to the different chemical compositions of the two buffer solutions. In fact, Mcllvaine is a citrate-phosphate buffer, while Trizma- $\mathrm{HCl}$ is a buffer solution containing chlorides (Table 1) which, in turn, may contribute to enhance oxidation half-cell reactions at the anode, including those determining the release of metals from the electrodes. Halides, such as chlorides, are indeed aggressive anions that may damage the thin oxide layer on the passivated metal surface of the electrodes, whose function is that of protecting the metal against corrosion. Our results seem to confirm that, at neutral $\mathrm{pH}$, the use of higher frequencies may markedly suppress corrosion of stainless steel electrodes during $\mathrm{OH}$ of solutions containing chloride compounds. Alternatively, it has been suggested that Titanium, which is considered to have high corrosion resistance and biocompatibility characteristics, could be the material-of-choice for chloride environments under conventional $\mathrm{OH}$ (Samaranayake et al., 2005).

The electrical conductivity of the heating medium is the main parameter controlling the heating rate in an ohmic heating process. It is defined as the ability to conduct electric current and depends on both the ionic strength and temperature. Tables 4 and 5 show the effect of electrical conductivity on the corrosion rate when solutions of both Trizma- $\mathrm{HCl}$ and Mcllvaine buffer $(\mathrm{pH}=7)$ were ohmically heated at fixed field strength and at different frequencies. From the results it can be noticed that, at a fixed field strength applied, the flux of metal ions increases with increasing electrical conductivity of the medium, regardless the frequency of the current signal. It is likely due to the higher current flow that passes through the medium with higher conductivity that, in turn, affects the charging rate of the double-layer capacitance. More in detail, according with findings of Morren et al. (2003), the socalled threshold time, which is defined as the time required to charge the double layer of the chamber, depends mainly on the current through the chamber and the value of the double-layer capacitance. Therefore, as the double layer capacitance of a stainless steel electrode is approximately $30 \mu \mathrm{F} / \mathrm{cm}^{2}$ (Gileadi, 1993b), the greater is the current flow, that is, the greater is the charge transfer per unit of time, the faster is the charging process of the double layer capacitor.

Our results also highlight that in both conventional and pulsed $\mathrm{OH}$ of Trizma-HCl buffer, the flux of iron ions increases significantly ( $p \leq 0.05$ ) when the conductivity increases from 1 to $5 \mathrm{mS} / \mathrm{cm}$. In the same heating medium, however, the flux of both chromium and nickel ions increases significantly $(p \leq 0.05)$ only when the conductivity increases from 1 to $3 \mathrm{mS} / \mathrm{cm}$ while no significant $(p>0.05)$ flux increases can be noted for further conductivity increases of up to $5 \mathrm{mS} / \mathrm{cm}$. In addition, the concentrations of chromium and nickel are below the limit of detection of the ICP-MS when higher frequencies are used. On the other hand, for $\mathrm{OH}$ of Mcllvaine buffer, the flux of all the metal ions increases significantly ( $p \leq 0.05$ ) when the conductivity increases from 1 to $5 \mathrm{mS} / \mathrm{cm}$ at lower frequencies. At higher frequencies, while the flux of iron ions increases significantly ( $p \leq 0.05$ ) only when the conductivity is above $3 \mathrm{mS} / \mathrm{cm}$, the concentration of chromium and nickel are kept below the limit of detection of the ICP-MS for all values of conductivity. Overall, for both heating media results of Tables 4 and 5 confirm that

Table 5

Flux of Fe, $\mathrm{Cr}$, and Ni in Mclvaine buffer solution $(\mathrm{pH}=7)$ as a function of the electrical conductivity and frequency $(f) . E=40 \mathrm{~V} / \mathrm{cm} ; T_{i}=25{ }^{\circ} \mathrm{C} ; T_{f}=90{ }^{\circ} \mathrm{C}$.

\begin{tabular}{|c|c|c|c|c|c|c|}
\hline \multirow[t]{3}{*}{ Metallic element } & \multicolumn{6}{|c|}{ Corrosion rate $\cdot 10^{7}\left(\mathrm{mg} / \mathrm{mm}^{2} / \mathrm{s}\right)^{*}$} \\
\hline & \multicolumn{3}{|l|}{$f=50 \mathrm{~Hz}$} & \multicolumn{3}{|l|}{$f=25 \mathrm{kHz}$} \\
\hline & $\sigma=1 \mathrm{mS} / \mathrm{cm}$ & $\sigma=3 \mathrm{mS} / \mathrm{cm}$ & $\sigma=5 \mathrm{mS} / \mathrm{cm}$ & $\sigma=1 \mathrm{mS} / \mathrm{cm}$ & $\sigma=3 \mathrm{mS} / \mathrm{cm}$ & $\sigma=5 \mathrm{mS} / \mathrm{cm}$ \\
\hline $\mathrm{Fe}$ & $1.709^{\mathrm{a}, \mathrm{A}}(0.470)$ & $6.387^{\mathrm{b}, \mathrm{A}}(0.980)$ & $24.560^{\mathrm{C}, \mathrm{A}}(2.130)$ & $0.074^{\mathrm{a}, \mathrm{B}}(0.010)$ & $0.125^{\mathrm{a}, \mathrm{B}}(0.021)$ & $0.230^{\mathrm{b}, \mathrm{B}}(0.027)$ \\
\hline $\mathrm{Cr}$ & $0.234^{\mathrm{a}}(0.062)$ & $1.342^{\mathrm{b}}(0.163)$ & $2.356^{\mathrm{C}}(0.271)$ & $<\mathrm{LOD}$ & $<$ LOD & $<$ LOD \\
\hline $\mathrm{Ni}$ & $0.152^{\mathrm{a}}(0.057)$ & $1.167^{\mathrm{b}}(0.212)$ & $2.295^{\mathrm{C}}(0.470)$ & $<$ LOD & $<$ LOD & $<$ LOD \\
\hline
\end{tabular}

a-b-c Means with different superscript lowercase letters for each frequency value and metallic element are significantly different $(p \leq 0.05)$.

${ }^{\text {A-B }}$ Means with different superscript uppercase letters for each metallic element and $\sigma$ values and different frequencies are significantly different ( $p \leq 0.05$ ).

LOD means Limit of Detection.

* Numbers in parentheses indicate standard deviations of mean $(n=6)$ corrosion rate. 
Table 6

Flux of Fe, $\mathrm{Cr}$, and Ni in Mclvaine buffer solution $(\sigma=3 \mathrm{mS} / \mathrm{cm})$ as a function of $\mathrm{pH}$ and frequency $(f) . E=40 \mathrm{~V} / \mathrm{cm} ; T_{i}=25{ }^{\circ} \mathrm{C} ; T_{f}=90{ }^{\circ} \mathrm{C}$.

\begin{tabular}{lrrlll}
\hline Metallic & & Corrosion rate $\cdot 10^{7}\left(\mathrm{mg} / \mathrm{mm}^{2} / \mathrm{s}\right)^{*}$ & & \\
\cline { 2 - 3 } element & $f=50 \mathrm{~Hz}$ & & $f=25 \mathrm{kHz}$ & \\
\cline { 2 - 3 } \cline { 5 - 6 } & $\mathrm{pH}=3.5$ & $\mathrm{pH}=7.0$ & & $\mathrm{pH}=3.5$ & $\mathrm{pH}=7.0$ \\
\cline { 2 - 3 } & $36.777^{\mathrm{a}, \mathrm{A}}(2.450)$ & $6.387^{\mathrm{b}, \mathrm{A}}(0.980)$ & & $0.301^{\mathrm{a}, \mathrm{B}}(0.033)$ & $0.125^{\mathrm{b}, \mathrm{B}}(0.021)$ \\
$\mathrm{Fe}$ & $2.211^{\mathrm{a}}(0.450)$ & $1.342^{\mathrm{b}}(0.163)$ & $<$ LOD & $<$ LOD \\
$\mathrm{Cr}$ & $3.9043^{\mathrm{a}}(0.480)$ & $1.167^{\mathrm{b}}(0.212)$ & $<$ LOD & $<$ LOD \\
$\mathrm{Ni}$ & & &
\end{tabular}

$\overline{\mathrm{a}-\mathrm{b}-\mathrm{c}}$ Means with different superscript lowercase letters for each frequency value and metallic element are significantly different ( $p \leq 0.05$ ).

${ }^{\mathrm{A}-\mathrm{B}}$ Means with different superscript uppercase letters for each metallic element and $\mathrm{pH}$ and different frequencies are significantly different $(p \leq 0.05)$.

LOD means Limit of Detection.

* Numbers in parentheses indicate standard deviations of mean $(n=6)$ corrosion rate.

high-frequency pulsed $\mathrm{OH}$ is capable of significantly $(p \leq 0.05)$ reducing corrosion rates, when compared with low-frequency conventional $\mathrm{OH}$.

The $\mathrm{pH}$ of the heating medium also affects electrode corrosion. Table 6 shows the flux of metal ions in Mcllvaine buffer solutions $(\sigma=3 \mathrm{mS} / \mathrm{cm})$ as a function of the $\mathrm{pH}$ at a fixed field strength and for different frequencies of the current signals. As can be seen, regardless of the applied frequency, acidic conditions (i.e. at $\mathrm{pH}=3.5$ ) seem to facilitate electrode corrosion resulting in a significantly $(p \leq 0.05)$ higher flux of metal ions than neutral conditions (i.e. at $\mathrm{pH}=7$ ). This can be explained by knowing that lower $\mathrm{pH}$ values mean higher concentration of hydrogen ions at the cathode. As a result, it is likely that the cathodic half-reaction (Eq. (2)) could couple with the anodic halfreaction (Eq. (3)) resulting in accelerated corrosion and hydrogen generation (Eq. (4)) compared to those at the neutral $\mathrm{pH}$ value (Samaranayake \& Sastry, 2005). However, in this work it was not possible to detect hydrogen/gas accumulation in the headspace of the ohmic heater since this was open to the atmosphere.

Cathodic half-reaction:

$2 H_{(a q)}^{+}+2 e^{-} \leftrightarrow H_{2(\mathrm{~g})}$

Anodic half-reaction:

$M_{(s)} \leftrightarrow M_{(a q)}^{2+}+2 e^{-}$

Overall reaction:

$M_{(s)}+2 H_{(a q)}^{2+} \leftrightarrow M_{(a q)}^{2+}+H_{2(g)}$

where $M=\mathrm{Fe}, \mathrm{Cr}$, or Ni.

According to our findings, Samaranayake and Sastry (2005), investigating the effect of $\mathrm{pH}(3.5,5.0$, and 6.5) under conventional $(60 \mathrm{~Hz}) \mathrm{OH}$ on the corrosion resistance of several electrode materials such as

Table 7

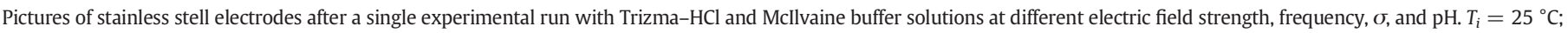
$T_{f}=90{ }^{\circ} \mathrm{C}$.

\begin{tabular}{|c|c|c|c|c|c|c|c|}
\hline \multirow[t]{2}{*}{$\mathrm{OH}$ conditions and heating medium } & & \multicolumn{2}{|c|}{$\sigma=1 \mathrm{mS} / \mathrm{cm}$} & \multicolumn{2}{|c|}{$\sigma=3 \mathrm{mS} / \mathrm{cm}$} & \multicolumn{2}{|c|}{$\sigma=5 \mathrm{mS} / \mathrm{cm}$} \\
\hline & & $20 \mathrm{~V} / \mathrm{cm}$ & $40 \mathrm{~V} / \mathrm{cm}$ & $20 \mathrm{~V} / \mathrm{cm}$ & $40 \mathrm{~V} / \mathrm{cm}$ & $20 \mathrm{~V} / \mathrm{cm}$ & $40 \mathrm{~V} / \mathrm{cm}$ \\
\hline \multirow[t]{3}{*}{ Conventional low frequency $(50 \mathrm{~Hz}) \mathrm{OH}$} & $\begin{array}{l}\text { Trizma-HCl } \\
(\mathrm{pH} \mathrm{7.0)}\end{array}$ & & & & & & \\
\hline & $\begin{array}{l}\text { Mcllvaine } \\
(\mathrm{pH} 7.0)\end{array}$ & & & & & & \\
\hline & $\begin{array}{l}\text { Mcllvaine } \\
(\mathrm{pH} 3.5)\end{array}$ & - & - & - & & - & - \\
\hline \multirow[t]{3}{*}{ Pulsed high frequency $(25 \mathrm{kHz}) \mathrm{OH}$} & $\begin{array}{l}\text { Trizma-HCl } \\
(\mathrm{pH} \mathrm{7.0)}\end{array}$ & - & & - & & - & \\
\hline & $\begin{array}{l}\text { Mcllvaine } \\
(\mathrm{pH} 7.0)\end{array}$ & - & & - & & - & \\
\hline & $\begin{array}{l}\text { Mcllvaine } \\
(\mathrm{pH} 3.5)\end{array}$ & - & - & - & & - & - \\
\hline
\end{tabular}


titanium, platinized-titanium, stainless steel and graphite, found that all the electrode materials exhibited intense electrode corrosion at $\mathrm{pH} 3.5$ compared to that of the other $\mathrm{pH}$ values. However, while graphite and stainless steel electrodes exhibited pronounced corrosion rates and hydrogen generation at all $\mathrm{pH}$ values, titanium and platinized-titanium electrodes showed lower corrosion rates which were not significantly different for all $\mathrm{pH}$ values tested.

This suggests that acidic food products, such as most fruit juices, will face higher problems with electrode material migration than non-acidic products of the same electrical conductivity, when $\mathrm{OH}$ is carried out under conventional low frequency of the current signal using electrochemically active electrode material such as stainless steel. In such a case, the use of higher frequency pulsed $\mathrm{OH}$, such as the one used in this work, may be an interesting way for markedly reducing the extent of electrode corrosion and electrochemical phenomena which typically occur at the electrode/solution interface, regardless of the $\mathrm{pH}$ and electrode material.

\subsection{Effect of corrosion on electrode surface}

Beyond the problem related with food safety, corrosion can also cause serious damages to the electrodes, whose surface roughness can increase as a consequence of the metal release or deposition (Saulis, Rodaitè-Riševičienè, \& Snitka, 2007). This, in turn, can cause local electric field distortion and arching drastically limiting the lifetime of the electrodes (Roodenburg, Morren, Berg, \& de Haan, 2005b; Saulis et al., 2007) and, hence, reducing the feasibility of $\mathrm{OH}$ technology as an alternative for thermal processing of food products. This is evident from the observation of the pictures reported in Table 7 which show the effects of corrosion on the surface of stainless steel electrodes after the $\mathrm{OH}$ treatment at different field strength and frequency of both Trizma-HCl and Mcllvaine buffer solutions at different $\mathrm{pH}$ and $\sigma$ values. Each picture was taken after subjecting a new couple of electrodes to only one experimental run. In addition, each picture is representative of only one of the couple of electrodes used during $\mathrm{OH}$ since, under alternating current conditions, the cathode and anode interchange places according to the frequency. Therefore, the electrochemical reactions of oxidation and reduction occur alternatively at the same electrode site.

As it can be seen, according with results presented above, corrosion caused serious damage to the surface of the electrodes when connected with conventional low frequency generator, with it being more evident for the case of Trizma-HCl than for the Mcllvaine solution. Furthermore, the higher the field strength and conductivity, the greater the electrode corrosion observed. In particular, due to the greater aggressiveness of the Trizma- $\mathrm{HCl}$ buffer solution (likely due to the presence of chlorides) with respect to the Mcllvaine solution, insoluble brown deposits can be also seen on electrode surfaces, indicating the possible formation of iron (III) oxide. Similar results have been reported by Assiry et al. (2006) during conventional low frequency $(60 \mathrm{~Hz}) \mathrm{OH}$ of a citrate-phosphate solution added with $\mathrm{NaCl}$.

Results of Table 7 also show that the electrode surface exposed during $\mathrm{OH}$ to acidic Mcllvaine solutions showed a slightly greater degree of corrosion than that exposed to the solution at neutral $\mathrm{pH}$. On the other hand, the pictures of the electrodes after $\mathrm{OH}$ at higher frequency values show no appreciable difference regardless the field strength applied, type of buffer, $\mathrm{pH}$ and conductivity of the heating medium.

Finally, by comparing pictures taken at the two operative frequencies for the heating media and processing conditions investigated, it can be seen that stainless steel electrodes exhibit corrosion with conventional low frequency $\mathrm{OH}$, while no appreciable effect appeared when operated under higher frequency pulsed $\mathrm{OH}$.

\section{Conclusions}

In the present work, the effects of electrical and product parameters on the rate of metal release from the stainless steel electrodes of an ohmic heater were examined with conventional low $(50 \mathrm{~Hz})$ frequency and pulsed high $(25 \mathrm{kHz}$ ) frequency $\mathrm{OH}$. The results showed that the flux of metal ions increased under more acidic conditions and with increasing field strength values applied and electrical conductivity of the heating medium. In addition, the extent of the electrochemical phenomenon occurring at the electrode-solution interface markedly depended on the presence of halides, such as chlorides, in the composition of the heating medium. However, the frequency of the current signal appeared to be the most important parameter. Indeed, in comparison with conventional low frequency $\mathrm{OH}$, the use of sufficiently large frequencies such as those provided by high frequency pulsed $\mathrm{OH}$, reduces the time available for charging the double layer capacitor. This avoids or reduces the extent of electrochemical reactions at the electrode interface, minimizing corrosion and leakage of metals to the medium.

For future work, similar experiments should be carried out with real foods in order to minimize, for each case, the extent of the electrochemical reactions by optimizing the ohmic processing condition.

\section{Acknowledgments}

Thanks are due to Dr. Mauro Maria Capitoli, Dr. Cristina Quintelas and Prof. Teresa Tavares for their invaluable help with ICP-MS and AAS determinations.

\section{References}

Amatore, C., Berthou, M., \& Hebert, S. (1998). Fundamental principles of electrochemical ohmic heating of solutions. Journal of Electroanalytical Chemistry, 457, 191-203.

Assiry, A.M., Sastry, S. K., \& Samaranayake, C. P. (2006). Influence of temperature, electrical conductivity, power and pH on ascorbic acid degradation kinetics during ohmic heating using stainless steel electrodes. Bioelectrochemistry, 68, 7-13.

Ayadi, M.A., Leuliet, J. C., Chopard, F., Berthou, M., \& Lebouche, M. (2004). Continuous ohmic heating unit under whey protein fouling. Innovative Food Science \& Emerging Technologies, 5, 465-473.

Bockris, J. O'M, Reddy, A. K. N., \& Gamboa-Aldeco, M. (2002). The electrified interface. In J. O'M Bockris, A. K. N. Reddy, \& M. Gamboa-Aldeco (Eds.), Modern electrochemistry 2A. Fundamentals of electrodics (pp. 771-1015). New York: Kluwer Academic Publishers.

Eliot-Godrereaux, S.C., Zuberb, F., \& Goullieux, A. (2001). Processing and stabilisation of cauliflower by ohmic heating technology. Innovative Food Science \& Emerging Technologies, 2, 279-287.

Gileadi, E. (1993a). The ionic double-layer capacitance Cdl. In E. Gileadi (Ed.), Electrode kinetics for chemists, chemical engineers, and material scientists (pp. 185-224). New York: VCH Publishers, Inc.

Gileadi, E. (1993b). Electrode kinetics for chemists, chemical engineers, and material scientists. New York: VCH Publishers1-56081-561-2.

Icier, F., \& Ilicali, C. (2005). Temperature dependent electrical conductivities of fruit purees during ohmic heating. Food Research International, 38, 1135-1142.

Jun, S., Sastry, S., \& Samaranayake, C. P. (2007). Migration of electrode components during ohmic heating of foods in retort pouches. Innovative Food Science \& Emerging Technologies, 8, 237-243.

Leizerson, S., \& Shimoni, E. J. (2005). Stability and sensory shelf life of orange juice pasteurized by continuous ohmic heating. Journal of Agricultural and Food Chemistry, 53, 4012-4018.

Morren, J., Roodenburg, B., \& de Haan, S. W. H. (2003). Electrochemical reactions and electrode corrosion in pulsed electric field (PEF) treatment chambers. Innovative Food Science \& Emerging Technologies, 4, 285-295.

Pataro, G., Donsì, G., \& Ferrari, G. (2011). Aseptic processing of apricots in syrup by means of a continuous pilot scale ohmic unit. LWT - Food Science and Technology, 44 $1546-1554$.

Pataro, G., Donsì, G., \& Ferrari, G. (2012). Metal release from stainless steel electrodes of a PEF treatment chamber. Procedeedings of the International Conference Bio \& Food Electrotechnologies, BFE 2012 (pp. 26-30), Salerno (Italy), 26-28 September 2012.

Pereira, R., Martins, R., \& Vicente, A. (2008). Goat milk free fatty acids characterization during conventional and ohmic heating pasteurization. Journal of Dairy Science, 91, 2925-2937.

Pereira, R., \& Vicente, A. (2010). Envirnmental impact of novel termal and non-thermal technologies in food processing. Food Research International, 43, 1936-1943.

Roodenburg, B., Morren, J., Berg, H. E., \& de Haan, S. W. H. (2005a). Metal release in a stainless steel Pulsed Electric Field (PEF) system. Part I. Effect of different pulse shapes; theory and experimental method. Innovative Food Science \& Emerging Technologies, 6, 327-336.

Roodenburg, Morren, J., Berg, H. E., \& de Haan, S. W. H. (2005b). Metal release in a stainless steel pulsed electric field (PEF) system. Part II. The treatment of orange juice; related to legislation and treatment chamber lifetime. Innovative Food Science E' Emerging Technologies, 6, 337-345.

Samaranayake, C. P., \& Sastry, S. K. (2005). Electrode and pH effects on electrochemical reactions during ohmic heating. Journal of Electroanalytical Chemistry, 577, 125-135. 
Samaranayake, C. P., Sastry, S. K., \& Zhang, Q. H. (2005). Pulsed ohmic heating: A novel technique for minimization of electrochemical reactions during processing. Journal of Food Science, 70, 460-465.

Saulis, Rodaitè-Riševičienè, R., \& Snitka, V. (2007). Increase of the roughness of the stainless-steel anode surface due to the exposure to high-voltage electric pulses as revealed by atomic force microscopy. Bioelectrochemistry, 70, 519-523.

Stancl, J., \& Zitny, R. (2010). Milk fouling at direct ohmic heating. Journal of Food Engineering, 99, 437-444.
Tzedakis, T., Basseguy, R., \& Comtat, M. (1999). Voltammetric and coulometric techniques to estimate the electrochemical reaction rate during ohmic sterilization. Journal of Applied Electrochemistry, 29, 821-828.

Yang, T. C. S., Cohen, J. S., Kluter, R. A., Tempest, P., Manvell, C., Blackmore, S. J., et al. (1997). Microbiological and sensory evaluation of six ohmically heated stew type foods. Journal of Food Quality, 20, 303-313.

Zoltai, P., \& Swearingen, P. (1996). Product development considerations for ohmic processing. Food Technology, 50, 263-266. 